\title{
Efficacy of Leadership Program for Head Nurses' Empowering and Supportive Role on Nurses' Work Engagement at Tanta Cancer Center Moshera E.Hanon ${ }^{1}$ Fouada M. Shabaan ${ }^{2}$, Karima A. El sayed ${ }^{3},$. Maha E. Shokir ${ }^{4}$ \\ ${ }^{1}$ Head nurse of surgical intensive care unit, Tanta Cancer Center \\ 2 Professor of Nursing Administration, Faculty of Nursing, Tanta University \\ ${ }^{3}$ Professor of Nursing Administration, Faculty of Nursing, Tanta University \\ ${ }^{4}$ AssistantProfessor of Nursing Administration, Faculty of Nursing, Tanta University
}

\section{Abstract}

Background: Oncology nursing services are performed in stressful work environments which affect their work engagement. Head nurses' empowerment and support are confirmed strategies for creating a positive workplace environment which in turn improve oncology nurses work engagement. The study aimed to determine the efficacy of leadership program for head nurses' empowering and supportive role on nurses' work engagement at Tanta Cancer Center (TCC). Research design: A quasi experimental design was utilized to meet the aim of this study. Setting: Study was conducted at TCC affiliated to Ministry of Health. Subjects: All (230) nursing staff include head nurse $(n=30)$ and nurses $(n=200)$ were participated in the study Tools: Three tools were used; (1) Head nurses' empowering and supportive role practice self-report (2) Nursing staff knowledge questionnaire (3) Nurses' work engagement scale. Results: Range $(80.9 \%-76.1 \%)$ of nursing staff preprogram had poor knowledge level about empowering and supportive roles of head nurses which highly statistically significantly at $(\mathrm{p}<0.001)$ improved post program to be range $(84.8 \%-79.1 \%)$ have good level of total knowledge. Head nurses range $(60 \%-50 \%)$ had unsatisfactory level of total empowering and supportive role practice preprogram, changed significantly at $(\mathrm{p}<0.01)$ post program to be range $(83.3 \%-73.3 \%)$ had satisfactory practice level. Preprogram nurses range $(65.5 \%$ 64\%) showed low engagement level for vigor, dedication and absorption respectively changed post program to be $66 \%, 63.5 \%$, and $67 \%$ respectively had high level of work engagement. Conclusion: The designed and implemented leadership program significantly improves head nurses' empowering and supportive role and oncology nurses' work environment. Recommendation: Head nurses periodical attend leadership program to update their empowering and supportive knowledge and practice.

Keywords: Oncology nurses, Oncology environment, Empowerment, Support, Work engagement.

Vol. 24 No. 1 , February 2022 


\section{Introduction}

Tanta cancer center provide specialized care for cancer patients through inpatient and outpatient services. It receives daily 500 patients from all delta governorates seeking different medical, nursing, laboratory, and radiological services. Oncology nursing services are performed in stressful work environments to meet the special needs of patients with cancer and their families. Stressful factors in the oncology specialty commonly include increased patient acuity, providing end-oflife care to patients with cancer and managing the treatment having serious side effects ${ }^{(1)}$. Beside patients' issues of anger and noncompliance with treatment as well as monitoring patients having pain and suffering ${ }^{(2)}$.Also poor working conditions such as work over load, shortage in professional nursing staff, insufficient materials, supplies and workplace training. All of these circumstances place a high emotional demand on oncology nursing staff which in turn, affects their work engagement ${ }^{(3)}$. Work engagement is a positive, satisfying, emotional state at work. It is characterized by vigor, dedication, and absorption.
Work-related vigor is exemplified by high energy levels, mental resilience, motivation, and perseverance. Dedication is characterized by a sense of meaning, passion, inspiration, pride, and challenge relating to one's work. Absorption involves full concentration and being deeply engrossed in work and it is characterized by the quick passage of time and a reluctance to detach oneself from work ${ }^{(4,5)}$. Engagement is a predictor of nurses' proactive behaviors, loyalty and performance, and financial returns. Further, engagement contributes to a variety of benefits for nurses and the organizations ${ }^{(6)}$.To ensure nurses work engagement it is necessary for health care organization to ensure working conditions that enhance work engagement. Head nurses with excellent empowering and supportive leadership skills are able to influence nurses to achieve certain objectives and goals, they can motivate them through their knowledge and skills to provide high quality care for cancer patients. Head nurses empowerment is a facilitative process where nurses perceive their head nurses to allow selfcontrol, self-regulation, self-management and self-leadership of nurses (7). Empowering head nurse delegate 
responsibility, encourage accountability, enable participative decision-making, share information, develop skills and coach for innovative performance ${ }^{(8)}$. Head nurses' empowering activities leads to various outcomes, such as nurses' empowerment, engagement, commitment, job satisfaction, role clarity, job insecurity, extra-role behaviors/ organizational citizenship and decrease turnover intentions ${ }^{(9)}$.Head nurses support refers to how nurses perceived that their head nurses value their work contributions and care about their comfort, well-being, and work related interests. Head nurses' support includes emotional support, informational support, and instrumental support. Emotional support pertains to how much a head nurse cares about nurses' feelings and listens to them. ${ }^{(10)}$. Informational support includes head nurse provides help, information and constructive feedback; giving guidance or advice about knowledge and skills for work and nurses believe that he/ she facilitates their further development (11). Instrumental support is providing aids, assistance, time, materials, and resources, services needed and financial aids to help nurses achieve their work goals (12). These forms of support are interrelated, for example a head nurse gives informational support such as verbal feedback in terms of recognition when nurse accomplishes a job. When receiving this recognition, the nurse feel that he or she is valued, esteemed and being cared by head nurse. When nurses perceive their head nurses as supportive will feel obliged to reciprocate by showing a favorable attitude in the form of work engagement ${ }^{(13)}$.

\section{Aim of study:}

Evaluate efficacy of leadership program for head nurses' empowering and supportive role on nurses' work engagement at Tanta Cancer Center

\section{Research hypothesis:}

The leadership program is expected to develop head nurses' empowering and supportive role and enhance nurses' work engagement.

\section{Subjects and Method}

\section{Study design:}

Quasi experimental research design was used to achieve the aim of the present research. Such design fits the nature of the problem under investigation.

\section{Setting:}

The present study was conducted at Tanta cancer center (TCC) affiliated to Ministry of Health. TCC beds capacity was (140). TCC included departments of medical, 
surgical, pediatric, in addition to operation room (OR), medical, surgical, and pediatric intensive care units (ICUs). TCC also included outpatient clinics, chemotherapy and early detection units.

\section{Subject:}

The study subjects consisted of all (230) nursing staff include head nurse $(n=30)$ and nurses $(n=200)$ working in the previous mentioned setting.

\section{Tools:}

The data of the study collected using three tools:-

Tool I: Head nurses' empowering and supportive roles practice self-report.

This tool developed by the researcher based on Nasurdin $(2018)^{(10)}$, Ramos (2017) ${ }^{(14)}$ and Al Hasnawi (2016) ${ }^{(15)}$ and review of recent related literatures. It translated into Arabic language. It consisted of three parts

\section{Part 1: Characteristics data of head} nurses: as age, sex, marital status, department, level of education, years of experience, and previous attendance of leadership programs.

\section{Part 2: Head nurses' empowering role:}

to assesses head nurses' empowerment behavior. It consisted of (59) items divided into 6 subscale:
- Delegation of authority

- Accountability include

- Participative decision making

- Information sharing

- Skill development Coaching for innovative performance

Part 3: Head nurses' supportive role to assess head nurses' support for nurses to accomplish their work. It consisted of (28) items divided into 3 subscales:

- Emotional support

- Informational support

-Instrumental support

- Scoring system: Responses of head nurses for part 2 and part 3 were measured on a three points likert scale ranging from always done (3), sometimes done (2), and not done (1)Level of head nurses' each of empowering and supportive roles were determined as follow: Satisfactory level $>75 \%$ Unsatisfactory level $\leq 75 \%$

\section{Tool II: Nursing staff knowledge} questionnaire: This tool developed by the researcher guided by Nasurdin (2018) ${ }^{(10)}$, Bogaert $(2018)^{(16)}$, kim (2017) ${ }^{(17)}$ and review of literature to assess aspects of empowering and supportive role and work engagement. It consisted of (5o) questions in the form of multiple choice (25 questions) and true or false (25 
questions).These questions were classified

into 5 categories as follows:

- Oncology work environment.

- Head nurses' empowering role and behaviors.

- Head nurses' supportive behaviors Oncologynurses' work engagement.

- Importance and dimensions of work engagement.

Scoring system: Nursing staff answers were measured according to their correct answer take (1) score and wrong answer take (0) score.

Levels of their knowledge determined as follows:-

- Good knowledge >75\%

- Faire knowledge 60-75

- Poor knowledge $<60 \%$

Tool III: Nurses' work engagement scale: It was consisted of two parts.

Part I: characteristics data of nurses: as age, sex, marital status, department, level of education, years of experience.

\section{Part II: Utrecht Work Engagement}

Scale (UWES):It was developed by Schaufeli (2006) ${ }^{(18)}$ and reused by Wang (2019) (19) to assess nurses' work engagement level. It consisted of (20) items under 3 subscales:

-Work vigor include seven items.
-Work dedication include seven items. -Absorption include seven items.

Scoring system: Responses of nurses were measured on a five points Likert scale ranging from always (5) to never (1) .

Levels of nurses' work engagement was determined as follows:-

High engagement level $\quad>75 \%$

Moderate engagement level $\quad 60-75 \%$

Low engagement level $<75 \%$

Method:

Official permission to conduct the study from the director of TCC was obtained and submitted to the responsible authorities of the selected setting

\section{Ethical consideration:}

- Approval of the ethical committee at Faculty of Nursing was obtained.

- All participant were informed about the purpose of the study.

- An informed consent was taken from each participant in the study including the right to withdraw at anytime.

- Confidentiality and privacy was taken into consideration regarding data collection.

-The three tools (I, II and III) presented to a jury of five experts in the area of specialty to check content validity of the tools. The five experts were lecturers from 
Faculty of Nursing, Tanta University, Nursing Services Administration department.

-The expert's relevancy responses were represented in a four points rating score ranging from (4-1); 4 =strongly relevant, 3 $=$ relevant, $2=$ little relevant, and $1=$ not relevant. Necessary modifications were done including; clarification, omission of certain questions and adding others and simplifying work related words. The face validity was $94 \%$ for head nurses' empowering and supportive role practice self- assessment. For nursing staff knowledge questionnaire was $95 \%$ and was 94\%for nurses' work engagement scale.

-Reliability of tools was tested using Cronbach's Alpha and coefficient test and take mean average of scores, which must not be less than 3 score. Its value 0.79 for head nurses' empowering and supportive role practice self- assessment, 0.84 for nursing staff knowledge questionnaire, and 0.82 for nurses' work engagement scale.

-A pilot study was conducted on (3) head nurses and (20) nurses randomly selected to test the tools for clarity and applicability, not from study subjects. It was conducted two times to the same head nurses and nurses after two weeks later (test - retest) to assess reliability of tools. The first time was implemented after the development of the tools and the second time was implemented before starting the actual data collection to test the clarity, applicability, and relevance of the questions.

\section{Data collection:}

-Head nurses' empowering and supportive role practice self-report, tool (I) was used before and after implementation of program.

-Knowledge questionnaire about head nurses empowering and supportive role and nurses work engagement, tool (II) was used before and after implementation of program.

-Nurses' work engagement scale tool (III) was used before, implementation of program.

-The researcher collected data and gave direction of program for duration of 3 months (start from March month to May 2020.

\section{Construction of leadership program}

Putting of statement of instructional objectives, which derived from the assessed need of the sample and literature review. 


\section{Instructional objectives general}

The main objective of the program is to develop head nurses' empowering and supportive role and enhance nurses' work engagement.

\section{Specific objectives}

At the end of the program nursing staff

should be able to:

-Discuss nature of oncology work environment.

-Demonstrate head nurses' empowering role and behavior.

-Use of supportive behaviors.

-Recognize oncology nurses' work engagement.

-Illustrate importance and dimensions of work engagement.

\section{Program contents:}

The content was designed to provide knowledge related to empowering and supportive role of head nurse and nurses; work engagement through 5 sessions as follows:-

-Oncology work environment.

-Head nurses' empowering role and behavior.

-Head nurses' use of supportive role.

-Oncology nurses' work engagement.

-Importance and dimensions of work engagement.

\section{Selection of teaching methods}

The methods used were lecture, group discussion, and presentation.

Teaching aids used for attainment of program objectives were data show, and clinical examples.

\section{Implementation of program}

The study was carried on 30 head nurse and 200 nurses. The nursing staff was divided into ten groups. The program time was 5 hours for each group. Every session 1 hour. The program was conducted for nursing staff at conference hall of TCC or inside nurses' office at their departments as available. They preferred to start session at $11 \mathrm{am}-12 \mathrm{pm}$ as it was the most suitable time for them after finishing first necessary work. The nursing staff was informed about objectives of program. The researcher built good relationship and motivated them to participate and share in program activities.

\section{Results}

Table (1) shows nursing staff characteristics, the age, sex, marital status, department name, level of education, years of experience as well as attended previous leadership program. $40 \%$ of head nurses aged 30- 40 years old and $60 \%$ aged $>40$

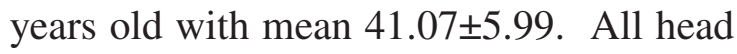


nurses were female, $80 \%$ married, $93 \%$ had bachelor degree. 7\% had master degree, $53 \%$ had $<20$ years of experience with mean experience 17.23 \pm 4 .42years, and $80 \%$ attended leadership program. While $51 \%$ of nurses aged $30-40$ years, and $38 \%$ aged <30, with mean 31.65 \pm 6.02 . They were female married, $78.5 \%$ had associated degree of nursing and $58.5 \%$ had $<10$ years of experience with mean experience10.98 \pm 7.73 .

Table (2) Levels of nursing staff total knowledge about dimensions of head nurses' empowering and supportive roles pre and post program. The table shows that there was highly statistically significant improvement of nursing staff level of total knowledge about dimensions of head nurses' empowering and supportive roles post than pre at $(\mathrm{p}<0.001)$. Preprogram range $(80.9 \%-76.1 \%)$ of nursing staff had poor level of knowledge for total of all dimensions of empowering and supportive roles which improved to be range $(84.8 \%$ $79.1 \%$ ) had good level of knowledge post program.

Table (3) Levels of head nurses empowering and supportive role practice pre and post program. The table shows that there was statistical significant improvement of head nurses of all items of practicing empowering and supportive role post than preprogram $(\mathrm{p}=0.007)$. Preprogram head nurses' range $(60 \%$ $50 \%$ ) showed unsatisfactory empowering role practice. But post program range $(83.3 \%$ - 76.7\%) showed satisfactory empowering role practice level. Preprogram equal head nurses range $(60 \%$ - 53.3\%) showed unsatisfactory supportive role practice for all items changed post program to be range $(83.3 \%$ - $73.3 \%)$ showed satisfactory supportive role practice level.

Table (4) Nurses' levels of work engagement dimensions pre and post program. The table shows that there was highly statistical significant change of nurses work engagement level for each dimension of work engagement post than preprogram at $(\mathrm{p}=<0.001)$. Preprogram range $(65.5 \%-64 \%)$ of nurses showed low level of vigor, dedication, and absorption dimensions of work engagement. They changed post program to be $66 \%, 63.5 \%$, $67 \%$ had high level of work engagement respectively for that dimensions. Figure (1)Levels of nursing staff total knowledge about head nurses' empowering and supportive roles pre and post program 
showed that most of nursing staff preprogram had poor knowledge level about empowering and supportive roles of head nurses. They improved post program to be majority have good level of knowledge.

Figure (2) Head nurses levels of total empowering and supportive role practice pre and post program. More than half of head nurses had unsatisfactory level of total empowering and supportive role practice preprogram, changed post program to be majority had satisfactory level.

Figure (3) Nurses levels of vigor dimension of engagement pre and post program. Preprogram more than two third of nurses showed low level of vigor dimension, changed to be more than two third had high level post program.

Figure (4) Nurses' levels of dedication dimension of engagement pre and post program. Preprogram more than two third of nurses showed low level of engagement dedication dimension, changed to be more than two third of them had high level post program

Figure (5) Nurses' levels of absorption dimension of engagement pre and post program. Preprogram more than two third of nurses showed low level of absorption dimension, changed to be more than two third of them had high level post program Figure (6)There was statistical significant positive correlation between nursing staff total knowledge and head nurses empowering and supportive roles preprogram at $(\mathrm{P}<0.001)$ and post program at $(\mathrm{p}=0.002)$ 
Table (1): Nursing staff characteristics

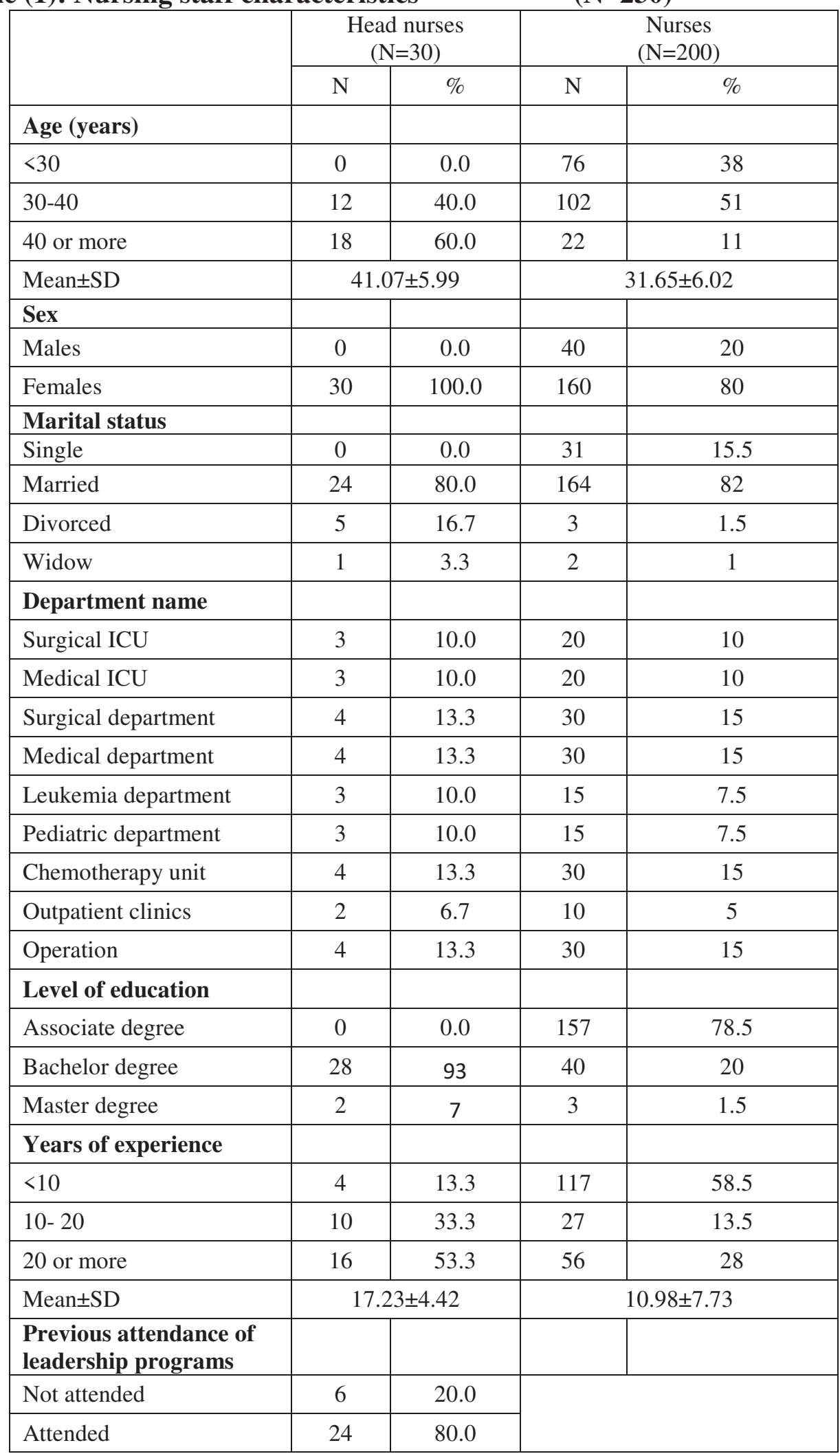


Table (2): Levels of nursing staff total knowledge about dimensions of head nurses' empowering and supportive roles pre and post program $(\mathrm{N}=230)$

\begin{tabular}{|c|c|c|c|c|c|c|c|c|}
\hline \multirow{3}{*}{ Dimensions } & \multicolumn{3}{|c|}{ Pre } & \multicolumn{3}{|c|}{ Post } & \multirow{2}{*}{\multicolumn{2}{|c|}{ Chi-square }} \\
\hline & Good & Fair & Poor & Good & Fair & Poor & & \\
\hline & $\mathrm{N} \%$ & $\mathrm{~N} \%$ & $\mathrm{~N} \%$ & $\mathrm{~N} \%$ & $\mathrm{~N} \%$ & $\mathrm{~N} \%$ & $\mathbf{X}^{2}$ & $P$-value \\
\hline Oncology environment & 9.6 & 13.9 & 76.5 & 81.3 & 10.9 & 7.8 & 259.803 & $<0.001 * *$ \\
\hline $\begin{array}{l}\text { Empowering role of head } \\
\text { nurses }\end{array}$ & 7.8 & 13.5 & 78.7 & 79.1 & 11.7 & 9.1 & 261.489 & $<0.001 * *$ \\
\hline $\begin{array}{l}\text { Supportive role of head } \\
\text { nurses }\end{array}$ & 10.9 & 13.0 & 76.1 & 84.8 & 10.0 & 5.2 & 274.368 & $<0.001 * *$ \\
\hline Nurses' work engagement & 10.4 & 12.6 & 77.0 & 81.7 & 11.3 & 7.0 & 261.337 & $<0.001 * *$ \\
\hline $\begin{array}{l}\text { Importance of work } \\
\text { engagement }\end{array}$ & 7.4 & 11.7 & 80.9 & 84.3 & 10.4 & 5.2 & 301.564 & $<0.001 * *$ \\
\hline
\end{tabular}

**Highly significant at $\mathbf{P}<0.001$

Table (3):Levels of head nurses empowering and supportive role practice pre and post program $(\mathbf{N}=30)$

\begin{tabular}{|c|c|c|c|c|c|c|c|c|c|c|}
\hline \multirow{3}{*}{$\begin{array}{c}\text { Empowering and } \\
\text { supportive role items }\end{array}$} & \multicolumn{4}{|c|}{ Pre } & \multicolumn{4}{|c|}{ Post } & \multirow{2}{*}{\multicolumn{2}{|c|}{ Chi-square }} \\
\hline & \multicolumn{2}{|c|}{ Satisfactory } & \multicolumn{2}{|c|}{$\begin{array}{c}\text { Un } \\
\text { satisfactory }\end{array}$} & \multicolumn{2}{|c|}{ satisfactory } & \multicolumn{2}{|c|}{$\begin{array}{c}\text { Un } \\
\text { satisfactory }\end{array}$} & & \\
\hline & $\mathrm{N}$ & $\%$ & $\mathrm{~N}$ & $\%$ & $\mathrm{~N}$ & $\%$ & $\mathrm{~N}$ & $\%$ & $X^{2}$ & P-value \\
\hline 1-Empowering role & 13 & 43.3 & 17 & 56.7 & 24 & 80.0 & 6 & 20.0 & 8.531 & $0.003 *$ \\
\hline Delegation of authority & 15 & 50 & 15 & 50 & 24 & 80 & 6 & 20 & 5.934 & $0.015^{*}$ \\
\hline Accountability & 14 & 46.7 & 16 & 53.3 & 25 & 83.3 & 5 & 16.7 & 8.864 & $0.003 *$ \\
\hline $\begin{array}{l}\text { Participative decision } \\
\text { making }\end{array}$ & 12 & 40.0 & 18 & 60.0 & 24 & 80.0 & 6 & 20.0 & 10.000 & $0.002 *$ \\
\hline Information sharing & 12 & 40.0 & 18 & 60.0 & 25 & 83.3 & 5 & 16.7 & 11.915 & $<0.001 * *$ \\
\hline Skill development & 13 & 43.3 & 17 & 56.7 & 25 & 83.3 & 5 & 16.7 & 10.335 & $<0.001 * *$ \\
\hline $\begin{array}{l}\text { Coaching for innovative } \\
\text { performance }\end{array}$ & 12 & 40.0 & 18 & 60.0 & 23 & 76.7 & 7 & 23.3 & 8.297 & $0.004 *$ \\
\hline 2-Supportive role & 14 & 46.7 & 16 & 53.3 & 24 & 80.0 & 6 & 20.0 & 7.177 & $0.007 *$ \\
\hline Emotional support & 13 & 43.3 & 17 & 56.7 & 22 & 73.3 & 8 & 26.7 & 5.554 & $0.018^{*}$ \\
\hline Informational support & 14 & 46.7 & 16 & 53.3 & 24 & 80.0 & 6 & 20.0 & 7.177 & $0.007 *$ \\
\hline Instrumental support & 12 & 40.0 & 18 & 60.0 & 25 & 83.3 & 5 & 16.7 & 11.915 & $<0.001 * *$ \\
\hline Total & 14 & 46.7 & 16 & 53.3 & 24 & 80.0 & 6 & 20.0 & 7.177 & $0.007 *$ \\
\hline
\end{tabular}

* Significant at $\mathbf{P}<0.01$ 
Table (4): Nurses' levels of work engagement dimensions pre and post program $(\mathrm{N}=\mathbf{2 0 0})$

\begin{tabular}{|c|c|c|c|c|c|c|c|c|}
\hline \multirow{3}{*}{$\begin{array}{c}\text { Work engagement } \\
\text { dimensions }\end{array}$} & \multicolumn{3}{|c|}{ Pre } & \multicolumn{3}{|c|}{ Post } & \multirow{2}{*}{\multicolumn{2}{|c|}{ Chi-square }} \\
\hline & High & Mild & Low & High & Mild & Low & & \\
\hline & $\mathrm{N} \%$ & $\mathrm{~N} \%$ & $\mathrm{~N} \%$ & $\mathrm{~N} \%$ & $\mathrm{~N} \%$ & N\% & $\mathbf{X}^{2}$ & P-value \\
\hline Vigor & 11.0 & 23.5 & 65.5 & 66.0 & 20.5 & 13.5 & 147.436 & $<0.001 * *$ \\
\hline Dedication & 10.0 & 26.0 & 64.0 & 63.5 & 19.0 & 17.5 & 133.123 & $<0.001 * *$ \\
\hline Absorption & 9.5 & 26.5 & 64.0 & 67.0 & 22.5 & 10.5 & 163.930 & $<0.001 * *$ \\
\hline
\end{tabular}

**Highly significant at $\mathbf{P}<0.001$

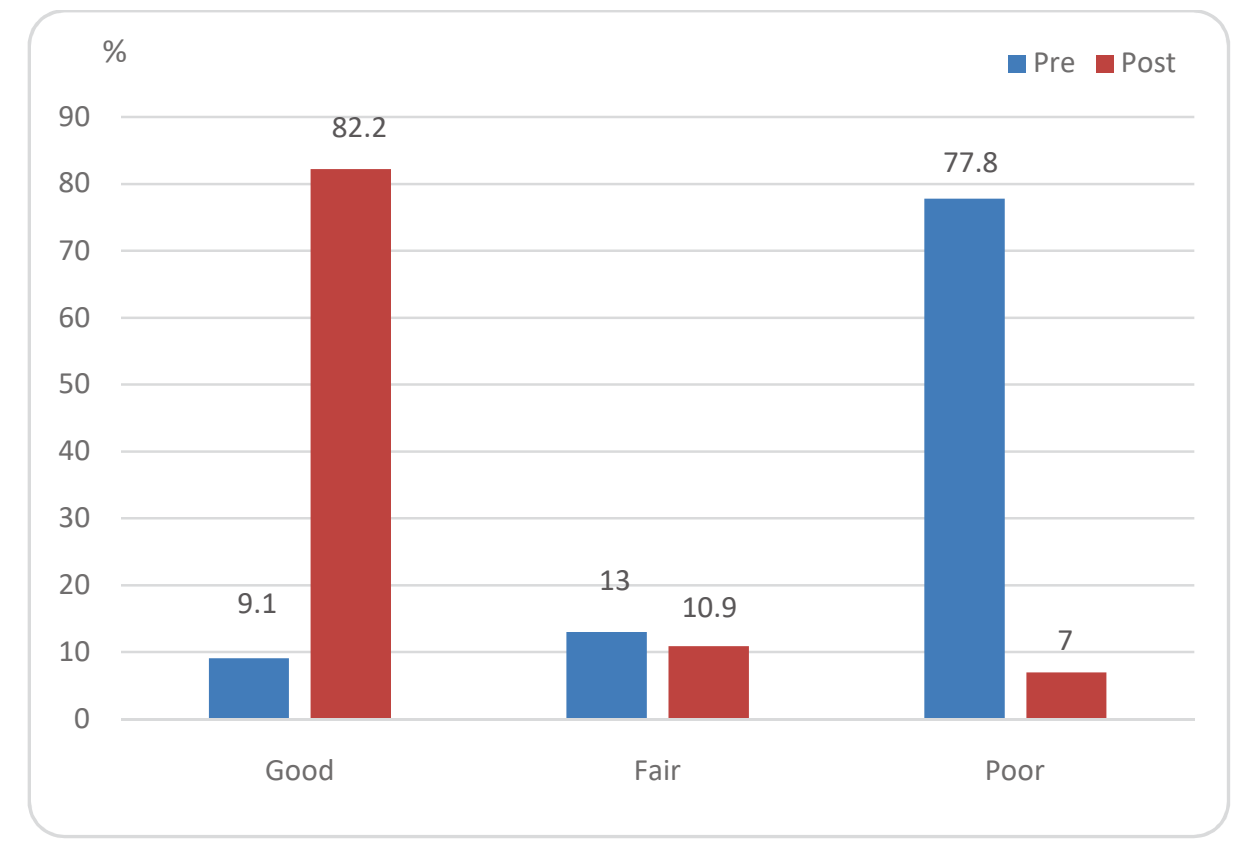

Figure (1): Levels of nursing staff total knowledge about head nurses' empowering and supportive roles pre and post program 


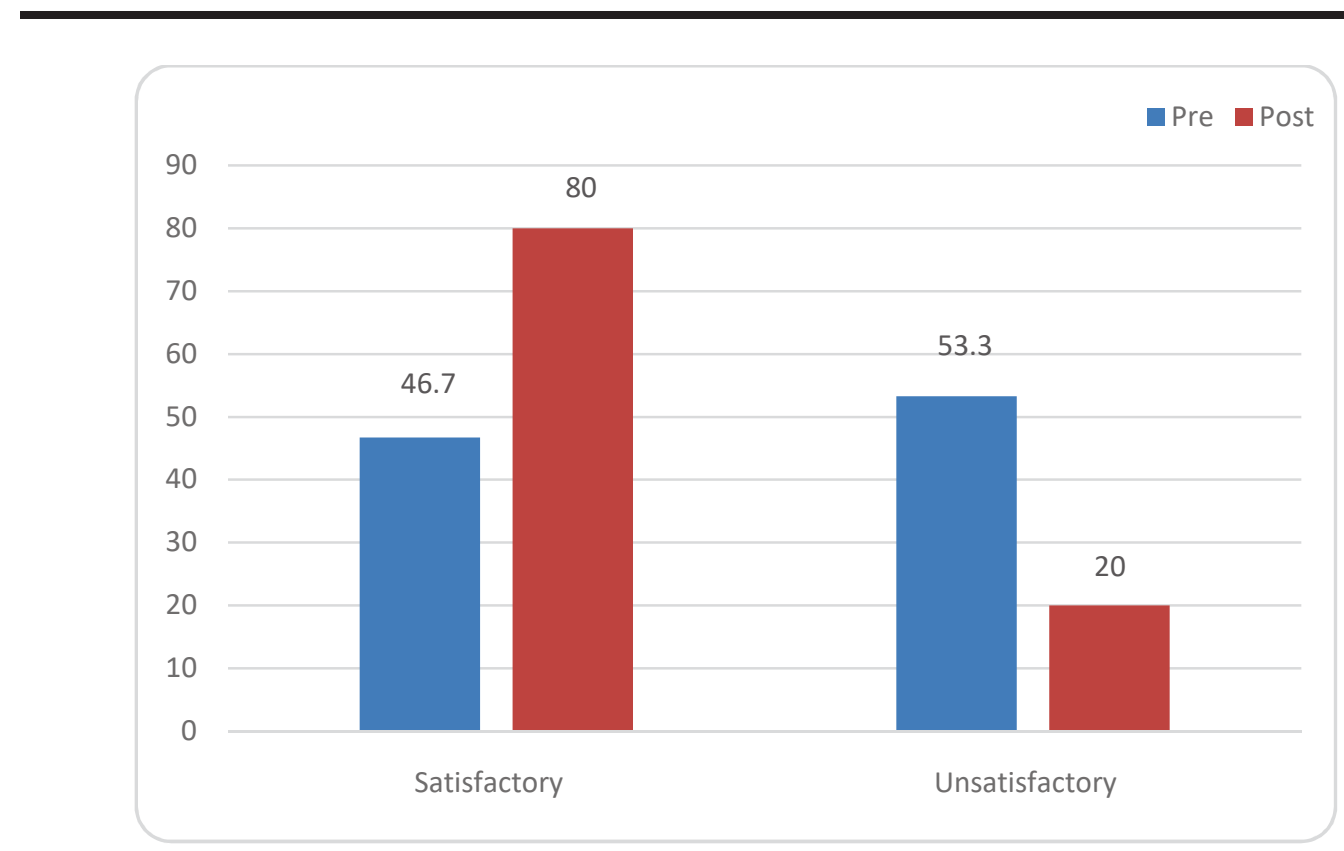

Figure (2): Head nurses levels of total empowering and supportive role practice pre and post program

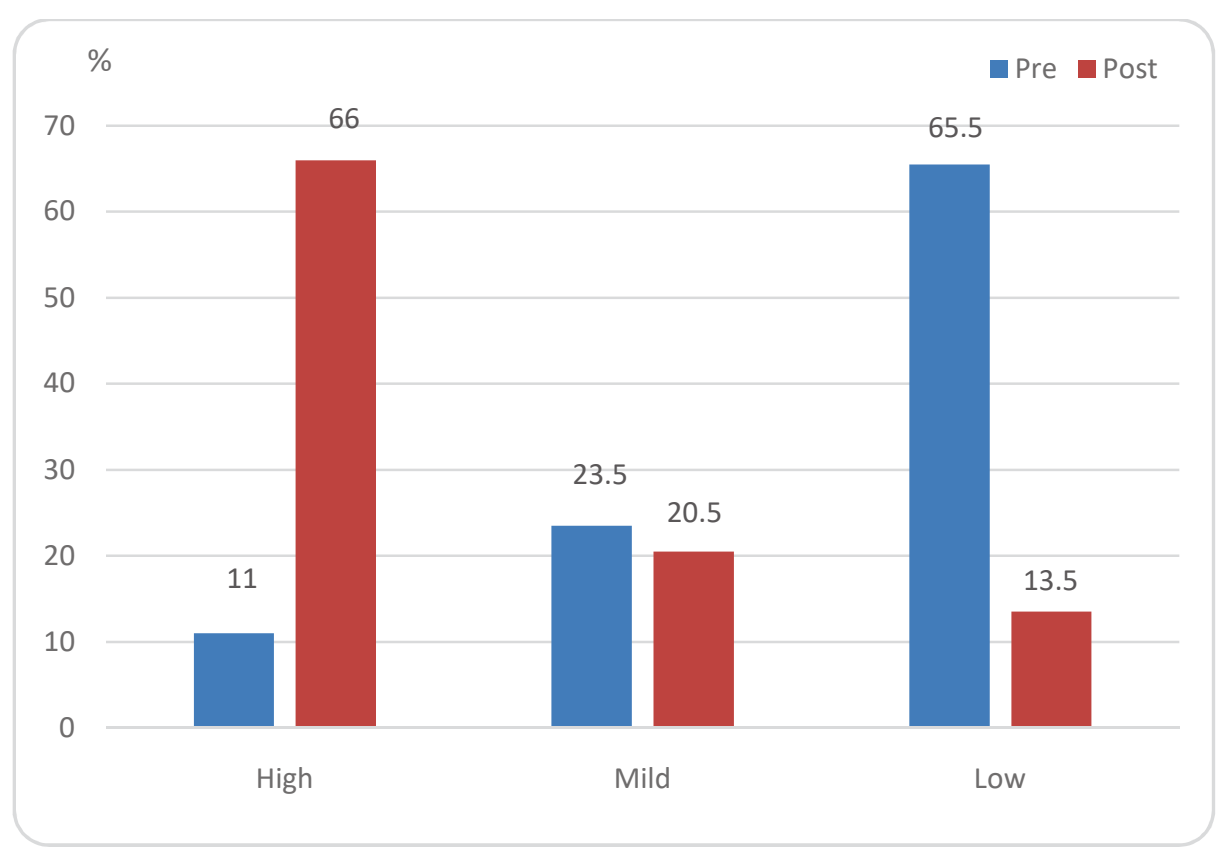

Figure (3): Nurses levels of vigor dimension of engagement pre and post program 


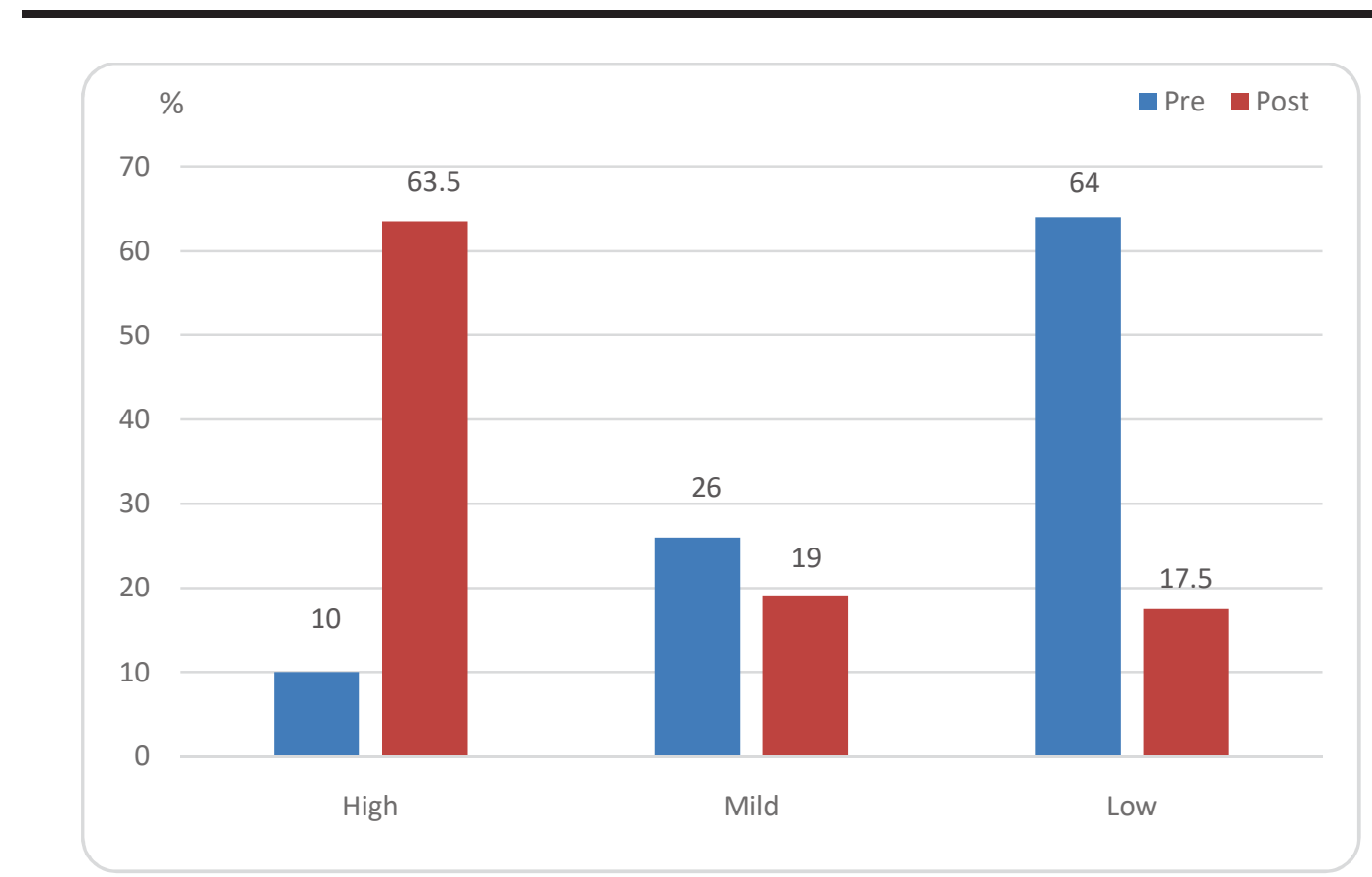

Figure (4):Nurses'levels of dedication dimension of engagement pre and post program

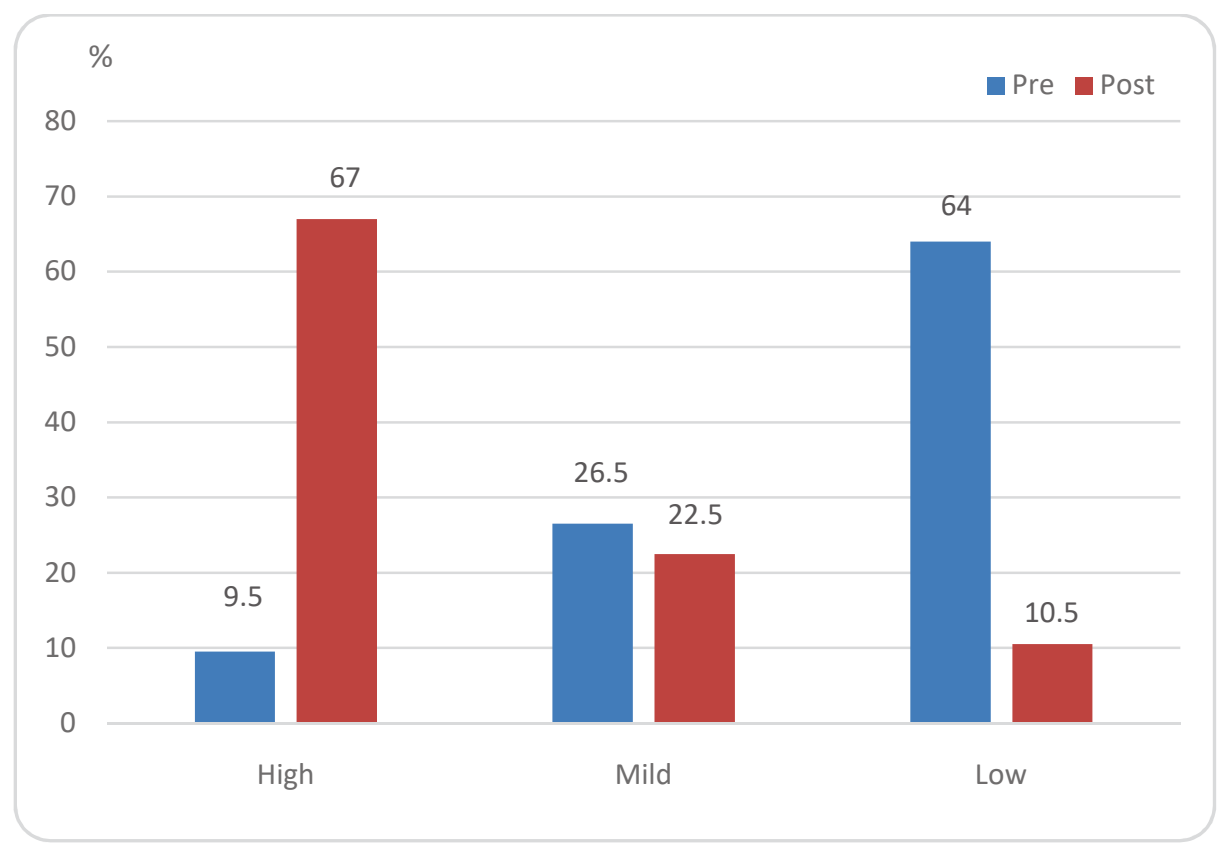

Figure (5): Nurses'levels of absorption dimension of engagement pre and post program 
Tanta Scientific Nursing Journal ( Print ISSN 2314 - 5595 ) ( Online ISSN 2735 - 5519 )
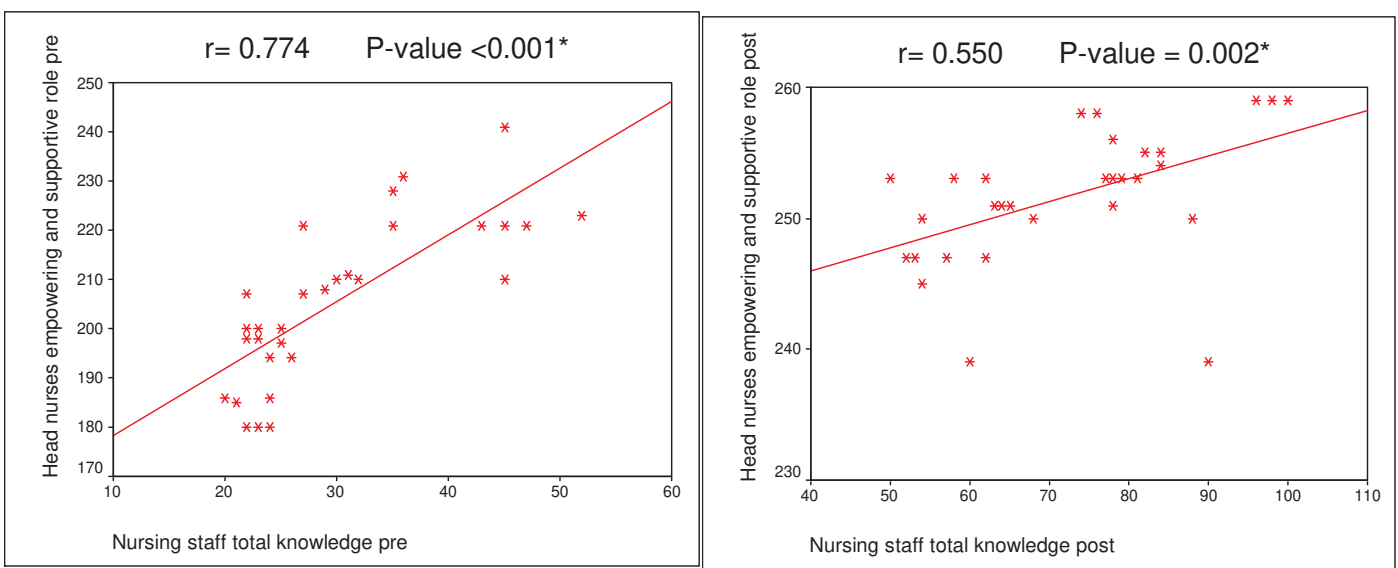

Figure (6): Correlation between nursing stafftotal knowledge and head nurses empowering and supportive rolepre and post program 


\section{Discussion}

Head nurses' empowerment and support are confirmed strategies for creating a positive workplace environment in any health care organization, which in turn improve the quality of services to the client. Also empowerment and support strategies are vital for improving nurses' involvement, reducing the fatigue of nurses and reduce the risk of burnout ${ }^{(20)}$. Oncology nurses confronting stressful working conditions as critical decision-making, managing the treatment having serious side effects, patients' issues of anger and noncompliance with treatment, monitoring patients having pain and suffering ${ }^{(1)}$.So the aim of this study was to examine the effect of head nurses' empowerment and support program on oncology nurses' engagement.

Result analysis indicated that most of present study nursing staff at preprogram showed poor level of knowledge about head nurses empowering and supportive role and nurses work engagement. Actually they were unequipped with enough knowledge about head nurses empowering and supportive role and nurses work engagement because they not recently attend any related orientation or training programs. But those nursing staff significantly improved immediately post attendance of present program sessions. The program gave them information about oncology environment, head nurses empowering role and behavior, head nurses supportive behavior, nurses' work engagement, and importance of work engagement .

Really the well-designed program attracted head nurses to develop their empowering and supportive role to enhance nurses' work engagement. Actually the program clarified to head nurses empowering role and behaviors, so that they start to delegate authority, enhance accountability, participate decisions and share information with nurses, develop nurses' skills, and coach nurse for innovative performance. Those head nurses understand their supportive role so that they start to provide emotional, informational, and instrumental support for nurses. Consequently nurses' work engagement was automatically enhanced.

Apparently the present study leadership program proved to be very important not only to improve head nurses empowering and supportive role but also to enhance oncology nurses' work engagement.Cziraki and Laschinger

(2015) $^{(8)}$ study about leader empowering behaviors and work Engagement: The mediating role of structural 
empowerment, stated that leadership strategies that create empowering working conditions are likely to retain nurses who are eligible to retire and attract future nurses to the profession. The leaders empowering behaviors influence nurses' work engagement by creating structurally empowering work environments. Adding that Zaki (2017) ${ }^{(21)}$ study about perceived nursing supervisor support and its relation to work engagement and turnover intention among staff nurses, found negative significant relationship between perceived nursing supervisor support and nurses' turnover intention at critical and non-critical units due to supervisor constructive feedback to nurses.

Nasurdin (2018) ${ }^{(10)}$ study about linking social support, work engagement and job performance in nursing, revealed that all three types ( organizational, supervisor, and peer) of social support were found to have positive effects on work engagement. Also Hammig (2017) ${ }^{(22)}$ study about health and well-being at work: the key role of supervisor support, reported that supervisor support is of major importance with regard to nursing staff health and well-being at work.

Current study result revealed that preprogram more than half of head nurses had unsatisfactory level of performing total empowering and supportive role, although most of head nurses are in middle age $30-40$ years which is full of energy and enthusiasm. Apparently their insufficient knowledge about delegation of authority, accountability, participative decision making, information sharing, skill development, and coaching for innovative performance negatively affected their practice. Most probably those head nurses are in need for either self -learning or leadership program to help them act as guides, facilitators and mentors to enhance staff's openness to changes in healthcare delivery approaches, productivity, and empowerment. Because those head nurses are responsible to provide emotional, informational and instrumental support to enhance nurses' work engagement.

Present study leadership program significantly improved head nurses understanding principles of self-control, self-regulation, self-management and improved their -leadership capabilities that contributed to strong influence on their practice for empowering and supportive roles to improve nurses' work engagement. In this context Farmawy\&Hassona (2018) ${ }^{(7)}$ study about the effect of head nurses' empowerment educational program on staff nurses' burnout, found that there was a positive effect of the educational 
program regarding empowerment for head nurses on the burnout of staff nurses. Also Burns (2016) (23) $^{(2 t u d y}$ about perceived organizational support and perceived supervisor support as antecedents of work engagement, found that perceived organizational and supervisor support were found to be predictive of work engagement.Contory to Jinmei and Sirakamon (2020) ${ }^{(24)}$ study about job satisfaction, leader empowering behaviors and work engagement among nurses in tertiary hospitals, kunming, the People's Republic of China, not support present study results but found that the overall head nurses' leader empowering behaviors and its six dimensions as perceived by nurses were at a high level and there was a moderate positive relationship between leader empowering behaviors and work engagement.

Results of present study revealed that more than two third of oncology nursesshowed low level of work engagement pre-program. Most probably those oncology nurses confronting conditions as critical decision-making, managing the treatment having serious side effects and patients' issues of anger and noncompliance with treatment. As well as monitoring patients having pain and suffering. Beside negative working conditions such as inadequate supplies and equipment, nursing shortage and growing number of patients and workload. These circumstances lead to an increase in nurses' job stress, job dissatisfaction, burnout, and decrease work engagement. Conservative estimates suggest that each disengaged nurse costs an organization $\$ 22,200$ in lost revenue as a result of lack of productivity. Nurse engagement is critical to the patient experience, clinical quality, and patient outcomes ${ }^{(25)}$.Siju, and Johansen (2019) ${ }^{(26)}$ study about oncology nurse engagement: the impact of a management education program, support the present study findings and reported that fifteen percent of nurses disengaged because the role of providing end-of-life care to patients with cancer places a high emotional demand on them. But Mousa and Elewa (2020) (4) study about relationship between nurse manager leadership style and staff nurses' work engagement, found that most staff nurses had high level of work engagement due to the supportive work environment which includes good communication and collaboration between staff nurses, justice, and skillful leaders that affect and reflect on staff.

Post program oncology nurses showed high level of work engagement due to head nurses start empowering and supporting them in their responsibility. 
Really the program promoted nurses' vigor, dedication, and absorption due to their enhanced relationship with their head nurses. Qatrunnada and Parahyanti (2018) $^{(27)}$ study about empowering leadership and work engagement: the role of psychological empowerment as a mediator, stated that leadership empowerment behavior influences employees' perceptions and experiences in the work environment to agreat extent. When leaders empower their employees they feel more competent and they experience meaning in their work.

Pattnaik and Panda (2020) $)^{(28)}$ study about supervisor support, work engagement and turnover intentions: evidence from Indian call centers, stated that supervisor support enhances work engagement of employees. As a result, employees are likely to show organizationally prescribed emotional dispositions.

\section{Conclusion}

Tanta Cancer Centerhead nurses were lacking empowering and supportive skills and practice while oncology nurses have low level of work engagement which reflected on their demand for leadership program to explain necessary information and train head nurses for practicing effective empowering and supportive role. The present study well designed program improved their knowledge and empowering and supportive role practice, as well as oncology nurses became absorbed, dedicated and energetic in their work.

\section{Recommendations}

In the light of the current study finding these recommendations are suggested:

\section{Hospital administration}

-Create strategies that promote supportive work environment such as rewards, flexible work schedules, fair pay and benefits, safe working conditions, and training.

-Perform regular assessment of head nurses skills, knowledge, and behavior before and after enrollment in their position.

\section{Head nurses}

-Periodical attend leadership program to update their empowering and supportive knowledge and practice.

-Develop and implement empowering strategies to engage their staff in work

\section{Oncology nurses}

-Seek to attendeducational programs about work engagement.

-Should focus on improving their knowledge and skills about vigor, dedication and absorption dimensions of work engagement. 


\section{Recommended research}

-Further research is done on the possible methods available for evaluation and measurement of the empowerment and support efforts. It is important that hospital can know decisively if their empowerment and support efforts are delivering the results they believe.

\section{References}

1-Nwozichi C, Ojewole F. Potential stressors in cancer care: perceptions of oncology nurses in selected teaching hospitals in Southwest Nigeria. African Journal of Medical and Health Sciences. $2015 ; 14: 130-4$.

2-Wazqar D. Oncology nurses' perceptions of work stress and its sources in a university-teaching hospital: A qualitative study. Wiley Nursing Open. 2019; 6(1):100-108.

3-Woonhwa K, Kiser-Larso N. Stress levels of nurses in oncology outpatient Unite. Clinical Journal of Oncology Nursing. 2016; 20 (2):158-164.

4-Mousa A, EldinFekry E, Elewa $\mathrm{H}$. Relationship between nurse manager leadership style and staff nurses' work engagement. Egypt Nursing Journal. 2020; 16(1):206 -13.

5-Seada A. Organizational role stress and work engagement among nurses in a selected hospital in Cairo. American Journal of Nursing Science.2017; 6 (1): 53-62.
6-Maar of $\mathrm{R}$, Mat $\mathrm{N}$. The effect of employee engagement on the job performance of nurses. Journal for Studies in Management and Planning. 2019; 5(8):16- 20.

7- Farmawy A , Nageeb S, Hassona F. The effect of head nurses' empowerment educational program on staff nurses' burn out. American Journal of Nursing 10.12691/ajnr-6-6-33.

8-Cziraki K, Laschinger $H$. Leader empowering behaviours and work engagement: The mediating role of structural empowerment . NursLeadersh (Tor Ont). 2015; 28(3):10-22.

9-Bukhari N, Afzal M, Azhar M, Gilani S. The role of nursing leader empowering behavior on work engagement and intent to stay in hospital. Journal of Health, Medicine and Nursing. 2108; 54(1):40- 43. 10-Nasurdin A. Linking social support, work engagement and job performance in nursing. International Journal of Business and Society. 2018; 19 (2):363-386.

11-Jolly P, Kong D, Kim K. Social support at work: An integrative review. Journal of Organizational Behavior.2021; 42(1):229251.

12-Qureshi M, Hamid K. Impact of supervisor support on job satisfaction: A moderating role of fairness perception. International Journal of Academic Research 
in Business and Social Sciences. 2017; 7(3):235-242.

13-Rezaei S, Jafari S. The relationship between quality of life and social support among nurses: A cross-sectional study. Industrial Psychiatry Journal. 2019; 28(2): 242-247.

14-Ramos A. Social support and engagement as antecedents of job satisfaction in nursing staff. Enfermeria Global. 2017. available at http://dx.doi.org/10.6018/eglobal.16.4.2607 71

15-Al Hasnawi H. Effect of the empowerment leadership's on job involvement reinforcement through a mediator role for strategic thinking skills. International Journal of Academic Research in Business and Social Sciences. 2016; 6(6): 189-220.

16-Bogaert P, Van heusden D, Slootmans S, Roosen I, Aken P, Guy H. Staff empowerment and engagement in a magnet recognized and joint commission international accredited academic center in Belgium: a cross-sectional survey. Health Services Research. 2018: 18:756.

17-Kim M. Organization-based self-esteem and meaningfulness mediate the effects of empowering leadership. Conference Paper. August

2017.DOI:10.1177/1548051818762337
18-Schaufeli W, Bakker A, Salanova M. The measurement of work engagement with a short questionnaire: a cross-national study. Educ. Psychol. Meas. 2006; 66(1):701-16.

19-Wang Y. The mediating role of inclusive leadership: work engagement and innovative behavior among chinese head nurses. Journal of Nursing Management. 2019; 27(5).DOI:10.1111/jonm.12754

20-Mudalla R, Othman W, Al Hassan N. Nurses' burnout: the influence of leader empowering behaviors, work conditions, and demographic traits. Inquiry. 2017 ; 54: 0046958017724944.

21-Zaki A. Perceived nursing supervisor support and its relation to work engagement and turnover intention among staff nurses. Egyptian Journal of Health Care. $2017 ; 8(2)$.

22-Hämmig O. Health and well-being at work: The key role of supervisor support. SSM - Population Health. 2017; 3(1): 393402.

23-Burns K. Perceived Organizational Support and Perceived Supervisor Support as Antecedents of Work Engagement Support as Antecedents of Work Engagement. Published Master Thesis. San Jose State University. 2016.

24-Jinmei D, Sirakamon S. Job satisfaction, leader empowering behaviors and work engagement among nurses in tertiary 
hospitals, Kunming, the People's Republic

of China. Nursing Journal. 2020; 47

(1):414- 427.

25-Dempsey C, Reilly B. Nurse engagement: What are the contributing factors for success?" OJIN: The Online Journal of Issues in Nursing.2016; 21(1): Manuscript 2.Available at: https://doi.org/10.3912/OJIN.Vol21No01M an02

26-Siju J, Johansen M. Oncology nurse engagement: The impact of a management education program. Clinical Journal of Oncology Nursing. 2019; 23(2): E39-E45.

27-Qatrunnada R, Parahyanti E. Empowering leadership and work engagement: The role of psychological empowerment as a mediator. Advances in Social Science, Education and Humanities Research. 2018; 229(1): 954-964.

28-Pattnaik S, Panda N. Supervisor support, work engagement and turnover intentions: evidence from Indian call centres. Journal of Asian Business Studies. 2020; 14 (5): 621-635.DOI 10.1108/JABS08-2019-0261 